\title{
A Preliminary Study on the Types of Uygur Mythology*
}

\author{
ZaiNahan·Abuduo \\ College of Uygur Language and Culture \\ Northwest Minzu University \\ Lanzhou, China \\ College of Humanities \\ Kashgar University \\ Kashgar, China
}

\author{
Lili Chen \\ Northwest Minzu University \\ Lanzhou, China
}

\begin{abstract}
In this paper, the Uygur mythology is classified by the authors and the motif analysis of the Creation theme will be analyzed. Among them, more references come from Chao Gejin and Wang Xianzhao's masterpiece "Wang's Catalog: Motif in China's mythology" and some of them are taken into use compared with Thompson's "Motif-Index of Folk Literature."
\end{abstract}

Keywords-Uygur mythology; type; preliminary study

\section{INTRODUCTION}

The study of myths in China began at the last century with the influence of Western academic trends and Mao Dun, Lu Xun, Zhou Zuoren and some other Chinese writers have done a relatively thorough study of the myth. Against the overall background, the study of Uygur mythology started in the middle and late of the last century. It can be determined that mythology is an important part of the folk oral text. Under China's overall cultural context, the study of ethnic minority folk culture plays an important role in modern cultural studies, which will help expand the research field and make the study of multinational folk literature more plentiful and vivid. Moreover, there is a certain foreshadowing role in establishing the myth of world fate community.

"The concept and category of mythology are far larger than literature, and it can't be included just by literature. It is not mythology that belongs to literature but literature that is attached to mythology." Nowadays, in the process of studying mythology from the perspective of interdisciplinary, we have learned knowledge from comparative linguistics, comparative religion, sociology, anthropology and so on. On the term "Mythology", Mahmoud Kashi gal, a famous Uygur scholar, has such a narrative in the Turkic Dictionary: for the mythology "caw", one of it is a narrative about something that is handed down orally and the other one is the story of a deified ancient hero. Although there are different statements and views on mythology at home and abroad, this is the understanding and explanation of the Uygur early scholars on mythology. "The Xinjiang Local Chronicles", "Journal of

* Northwest Minzu University, Research and innovation project of central special funded graduate students in 2017, the study of Uygur mythology, project number: Yxm2017003.
Xinjiang University (Uighur version)," Uighur classical literature " have begun do some research on the Uyghur myth from the beginning of 80 s, such as, "Myths and Legends of Ancient Times", "Myths about Wolves", "Characteristics of Uyghur Mythology", "Legends of Myths and Myths of Legends", "Philosophical Values in Uyghur Mythology", "Study of Uyghur-induced Myths" and so on.. Most of these articles have used the research methods of literature, and the content of the research is relatively abundant. Uygur mythology has accumulated some early data and papers in Braque (source), Meras (Heritage) and other periodicals, which has certain reference value. The following are the achievements in the study of Uygur Mythology:

\section{A. Classification Study}

In the "Preliminary research on Uighur myth", Abdukerim Lachmann does simple classification of Uighur myth in from the perspective of literature while in the paper "Female Images in Uighur Myths and Legends", Heteritius Usman introduced the typical female images of Uighur myths and legends from the perspective of literature and classified these images.

\section{B. Motif Research}

In "Wang's Catalog: Motif in China's mythology", chiefly edited by Chao Jinge and wrote by Wang Xianzhao, there are some records about the matrix of the Turkic and Uygur mythology. And the motif theme of the myth of the Uygur is classified in Wang Xianzhao's work "the chief theme of Chinese national mythology".

\section{History Research}

In the "History of Chinese Minority Literature" published in 2001, two Turkic myths are introduced and the conclusions of what time these two myths come from are given.

\section{Comparative Study}

Zhang Yue's thesis "Uggus Legend and Turkic Myths" uses a comparative method to explore Han Chinese mythologies that are similar to this one. The comparison between the Uyghur mythology "The Creation of the Female 
Nymph" and the Han Chinese mythology "Nuwa made human" compares the content and the motif of these two myths.

\section{E. Etymological Study}

$\mathrm{Li}$ Guoxiang's "debate on Uygur myth--from the etymological perspective" introduced the Uygur mythology, and put forward some views, such as the close relationship between Uyghur mythology and Uygur literature and so on.

\section{F. Folklore Studies}

Guo Haisha's essay "From Deity to hunan - An Inquiry into the Views of Women and Women in Uygur Mythology", uses folklore and folk literature to classify the sources of Uighur mythology, and discusses the transformation process of Uighur female nymph to human image. The Shamanism myths reflected in chansons de geste plum "the Oghuz" mainly introduces the bizarre birth of "wolf ancestor" "tree birth" and Oghuz.

Of course, it does not mean that only one method is used when discussing the article. The author summarizes the most prominent method, which aims to emphasize the basic method of research on the Uyghur mythology's current situation.

Foreign countries started earlier in studying Uighur mythology and also recorded more Uighur myths, such as, the Russian Orientalist, academician La DeLoof, Barto Reid, Xia Allenburg, Bunni Tamu, Kata Ubud, Malouf and so on.

\section{BEFORE THE ClASSIFICATION, WE HAVE TO DESCRIBE} THE CURRENT TEXT RECORDS OF THE UYGUR MYTHOLOGY

\section{A. The Situation Recorded in Uighur}

Uyghur mythological texts recorded in Uighur are mainly in the first volume of Xinjiang volume in 2015 issue of "China folk literature integration". In addition, Braque (fountainhead), Meras (Heritage) and other periodicals also have some early data.

\section{B. Uyghur Mythological Texts Recorded in Chinese}

There are some Chinese literature books, such as "Historical Records", "the book of former Han", "Chou Shu", "Sui Shu", "Tang Dynasty" and other historical classics, also record a large number of Uyghur myth.

\section{Uyghur Mythology Text Recorded in Foreign Language}

The Russian Orientalist, academician La DeLoof, Barto Reid, Xia Allenburg, Bunni Tamu, Kata Ubud, Malouf and Bolvarins also record some Uighur mythology texts in their works.

The main features of Uighur mythology:

- Firstly, The Uyghur mythology has documentary features. A large number of Uyghur mythological texts have been recorded in Chinese, Uighur, and Russian. In contrast, its oral creativity gradually weakens.

- Secondly, most texts in Uighur mythology are relatively short, unlike some Greek myths. Only a few of the myths are longer, such as the "The Legend of Ugos Khan."

- $\quad$ Thirdly, from the perspective of mythological content, some myths are fragmented and some myths are incomplete. Mythological oral features have the phenomenon that a myth is mixed by different myths contents and folk story.

\section{A. Creation Myth:}

A1. World separation type:

A1-1 Nymph Creates: t56 Earth and Apis

A1-2 Deity Creates: t1 Danglars and Cauchy

\section{A1-3 Bird Creates: t2 Osprey}

A1-4 Type of Deity and Human Separation: t1 Danglars and Cauchy; t5 the human ancestor was rushed to the world.

A2 Natural originality type:

A2-1 Geomorphic creativity:

A2-1-1 Deity creates: t1 Danglars and Cauchy

A2-1-1 Sea mud creates: t1 Danglars and Cauchy

A2-1-2 Bird creates: 2 Osprey

A2-2 Climate creativity: t11 Nymph of Esama; t12 Celestial Ruler Supreme Deity

A2-3 Creation of all things: t1 Danglars and Cauchy

A3 Mythology of the type of human origin

A3-1 Nymph Creates:

t56 Hawa Anam; t51 The nymph creates humans

A3-2 Physical metaplasia: t4 Kay Meyers

A3-3 Plant creates human: t1 Danglars and Cauchy

A3-4 Mixed species create human: t43[Sweden] Dosan Writes, Feng Chengjun translates, recorded in Histoire des Mongols Cauchy

A3-6 Danglars (Deity) creates human: t1 Danglars and

A3-7 Deity creates human: t3humanand horse creation

\section{B. Disaster and Hero Salvation Myth:}

B1 Human reproduction: $\mathrm{t} 25$ flood disaster; $\mathrm{t} 36$ giant

B2 Eliminating murder: $\mathrm{t} 15$ the appearance of Eticourt Hill; t15-1 (subtype) the appearance of Eticourt Hill

B3 Flood disaster: t52 Wuyun girl

B4 Earthquake: $\mathrm{t} 17$ why does the earthquake happen?

B5 The myth of shooting the sun ${ }^{1}$ : t80 Why there are ten suns in the sky

\footnotetext{
The folk shooting story was classified into folk tales by the Uighur tradition and the author categorizes it as a shooting myth.
} 
B6 The myth of drought:

B7 Mythology of Deity's War

B7-1 : Clog soil and water: $\mathrm{t} 1 \mathrm{~A}$ big stone in a great river

\section{Mythology of the Origin of Civilization}

C1 Clan and ancestor myth

C1-1 Induced by pregnancy:

C1-1-1 Sensitization: t79 the legends of uggiz Khan

C1-2 Marriage between human and animal: t19 the origin of high car people

C2 The emergence of the nation: $t 23$ the origin of the nation

C3 The emergence of language: t81 Qin and Ma Qin

C5 Salt and sewn myths: t34 Japas--Noah's third son

C6 Totem Myth: t18-1 Blue mane Wolf

C7 Agricultural production and life: t17-1 why does earthquake happen

C7 Taboo myths: $t 12$ the emperor of heaven

C8 Avoid sibling marriage: 16 Why is there an echo of the mountain?

C8 The concept of number: 117 why does earthquake happen

\section{Mythology of the Origin of Time and Space}

D1 Mythology of the origin of time

D1-1 Sun and month running: t8 Xirin girl; $t 7$ the sun and the moon

D1-2 The birth of the sun and the moon: t6 the princess became the moon,

D1-3 The birth of the stars: t10 Qi Li looking forward to stars(morning star)

\section{D2 Mythology of space origin}

D2-1 Multistorey sky Mythology: t11 Aisema angel; t1 Danglars and Cauchy; t17 Why does earthquake happen

D3 Mythology of the origin of history: t18 Blue mane Wolf; t18-1 Blue mane Wolf (subtype) the Legend of Goos Khan

\section{E The Myth of the Interconnection of Sky and Earth}

E1 The myth of the interconnection of sky and earth

E1-1 Weighing type: t8 Xirin girl

E2 The myth of heaven and earth disconnection: t56 Earth and Apis

E3 The myth of flying up to the heaven moon

E3-1 Morning glory type: t6 the princess becomes the girl

E3-2 Flying up to the heaven with black clouds: t53 Yun

F Myth of fate:

F1 Lost Paradise: t5 the human ancestors are rushed to the world

F2 The Mythology of the rendezvous of human and Deity: t51 The Nymph of heaven creates human beings

F3 The punishment of Deity: t51 The Nymph of heaven creates; $\mathrm{t} 25$ Flood disaster

F4 The reward of Deity: t51 The Nymph of heaven creates human beings

\section{G Variant Mythology}

G1 Immortal myth: t1 Danglars and Cauchy

G2 Mythology of Eternal Rebirth

G2-2-1 The Falcon chased the father: t13 a big stone that blocks the river

G2-2-2 Dragon turns to be a mountain: t14 Dragon mountain; t15 the appearance of Eticourt Hill

G3 Escape sibling marriage distortion: t16 why does the mountain have an echo?

\section{Deity and people of Deity}

"Wang's Catalog: Motif in China's mythology" divides the myth into 9 themes, 1, the world and the natural objects; 2,humanand human; 3, animals and plants; 4, natural phenomena and natural order; 5, social organization and social order; 6 , tangible and intangible culture; 7 , marriage and sex; 8 , disaster and war; 9, other motif. The author only does motif analysis of the following second topics:humanand human, human origin, time, place and other basic problems. In order to avoid the repetition of the motif, the author refers to the motif classification of the "Wang's Catalog: Motif in China's mythology".

\section{1) Human births}

a) Causes of human emergence:

First level motif: there are reasons for the generation of human beings: 11 Danglars and Cauchy

Second level motif: the generation of human is related to Deity: t1 Danglars and Cauchy

The generation of people is related to specific needs: $t 1$ Danglars and Cauchy

\section{b) The time of human generation}

First level motif: In ancient times, people were born: $\mathrm{t} 1$ Danglars and Cauchy

Second level motif: People are born when the world is formed: t1 Danglars and Cauchy, which is the same as Nahsi nationality

\section{c) The place of human birth}

First level motif: people are born at a specific other location 
Second level motif: People are produced in plants: $\mathrm{t} 1$ Danglars and Cauchy'; related race: the Drung

2) A person naturally exists or originates in a certain place

a) Natural existence of human beings

First level motif: The first person in the world: 15 the human ancestor was driven into the world

Second level motif: Ahumanancestor in Paradise: t5 the human ancestor was driven into the world

\section{b) People come from somewhere}

First level motif: People go to the world from the Heaven: t5 the human ancestor ${ }^{3}$ was driven into the world (The Naxi nationality, Kazak (human ancestors) and Salars have the same myths)

Second level motif: People descend from heaven: t5 the human ancestor was driven into the world

Third level motif: People are driven into the world because eat the forbidden fruit: $t 5$ the human ancestor was driven into the world The Kazakh (human ancestors), the Salars (human ancestors). A1331.1

\section{3) Creating people}

a) The time of creating people

First level motif: The time of creating people

Second level motif: creating people after specific events: t1 Danglars and Cauchy

Third level motif: Danglars creates human after saving Cauchy: t1 Danglars and Cauchy

\section{b) The cause of creating people}

First level motif: Creating people to manage the world (A1201): t3 the emergence of people and horses (Han, Salar and Shui nationality)

Third level motif: creating people to get rid of loneliness: t57 Deitydess creates human

Second level motif: Nymph creates human because of her loneliness: t57 Nymph creates human

\section{c) Human-creator} human

First level motif: Deity or people of divine character create

Second level motif: Deity creates human: t57 Nymph creates human

Third level motif: Nymph creates human: t57 Nymph creates human ${ }^{4}$

\footnotetext{
2 Naturally, trees without branches appear, and then Danglars orders the tree to issue branches, and then commands the person appearing on the branches.

The human ancestor and the deity live together in the heavens and are driven to the world after violating the taboos.

$4 \quad$ With the help of Allah, the nymph breathed a sigh of relief to the mud-made figure created by her self and gave Adam the life.
}

Danglars creates human; t1 Danglars and Cauchy

\section{d) The materials of creating human}

First level motif: Use inanimate objects as man-made materials

Second level motif: Create human being with mud: t57 Nymph creates human limbs

First level motif: Creates human by using specific physical

Second level motif: Create people with ribs: t57 Nymph creates human

Third level motif: making women with a man's ribs: t57 Nymph creates human

e) The measures of making people

First level motif: The measures of making people

Second level motif: Create human by order: t1 Danglars and Cauchy

f) Man-made results

First level motif: Come into life after being blown up

Second level motif: Come into life after Deity blowing up: t57 Nymph creates human

First level motif: Mud-made people come into being after being dried up

Second level motif: Mud-made people come into life after being blown by wind and being grilled by fires: $\mathrm{t} 3$ the emergence of people and horses

g) Other motifs related to man-making

First level motif: the time of creating human

Second level motif: it will takes thousands of years to create human: $\mathrm{t} 3$ the appearance of men and horses

First level motif: other motifs related to man-making

Second level motif: Devil Interference: $\mathrm{t} 3$ the appearance of men and horses

First level motif: the place of creating human

Second level motif: create people in the Heaven: $t 3$ the appearance of men and horses, Kirgiz and Mongolians

4) Birth produces people (produce people)

a) Deity or people of divine character produce human

First level motif: Deitys produce people (Temporarily no)

\section{b) Human give birth to human}

First level motif: Special human give birth to human: t4 Kaijmerge

Second level motif: Transformed human give birth to human: t4 Kaijmerge

Third level motif: The seeds in the waist fall onto the ground and come into life (No in cataloging): t4 Kaijmerge 
c) Animals give birth to human A1224,B631, T566 (Same as Thompson)

First level motif: Mammal creates human: $t 73$ the wolf are ancestors

Second level motif: The wolf creates human

d) Plants produce human T543 (Same as Thompson)

First level motif: The specific parts of trees give birth to human

Second level motif: branches produce human: t1 Danglars and Cauchy

The gall produces human: $\mathrm{t} 42$

e) Inanimate objects produce human T544(Thompson)

First level motif: water produces human: A1232.2.1, T546 (Same as Thompson)

Second level motif: sweats produce human: t4 Kaijmerge

First level motif: other motifs related with "Inanimate objects produce human"

Second level motif: Different kinds of objects produce human; the hill of two trees produces human: $t 43$

Third level motif: trees and soil create human

\section{f) Ovum produces human (Temporarily no)}

\section{g) Sense produces human} human

First level motif: sensitively natural phenomenon produces

Second level motif: produce human by sensitization

Third level motif: give birth to human by sensitive sunshine: 79 The Legend of Ukos Khan

Give birth to human by tree sense

First level motif: other motif related to sense birth

Second level motif: produce human by plant sense

Third level motif: trees produce human by sanitation: The Legend of Ukos Khan.

\section{CONCLUSION}

This paper classifies the recorded Uygur mythological texts by using typology and maternal theory. Uygur mythology can be roughly divided into 8 types: creation myth, disaster and hero salvation myth, civilization origin myth, time and space origin myth, heaven and earth transportation myth, fate myth, variant myth, and disaster and war. The type of Uygur myth is complete. The birth of human had peculiar thoughts in the early days of man. The author makes motif classification to reasons, time, places, materials, methods and results of the birth of humanin mythology text. This kind of classification basis refers more to the work W Catalogue of Chinese Myths Motif of Chao Gejin and Wang Xianzhao, and some of them are compared with Thompson's index of motifs of folk literature. The analysis of the motif of "birth of human" in Uygur mythology has a certain basic construction effect on the construction of Uygur mythology system. Although it doesn't have the secular utility, it can build bridge to the thinking of "birth of human" of the ancient people far away, establish a coordinate system of material and traceability for Uygur mythology and lay the foundation for the theoretical exploration of ancient ideological and cultural research.

\section{REFERENCES}

[1] Wang Qian. A Study of the Origin Path of Mythological Civilization. China Social Sciences Press. Beijing. 2015, page 13.

[2] Chao Jinge edits, Wang Xianzhao writes. "Wang's Catalog: Motif in China's mythology", China Social Sciences Press. Beijing. 2013, page411. 